\section{The present status and distribution of Long-tailed Macaque Macaca fascicularis aurea (Mammalia: Primates: Cercopithecidae) in Bangladesh}

\section{Tarik Kabir ${ }^{1}$ \& M. Farid Ahsan ${ }^{2}$}

${ }^{1}$ MPhil. Fellow, ${ }^{2}$ Professor, Department of Zoology, University of Chittagong, Chittagong, Bangaldesh

Email: ${ }^{1}$ bankmyna_chapai@yahoo.com, ${ }^{2}$ faridahsan55@ yahoo.com (corresponding author)

The Long-tailed or Crab-eating Macaque (Macaca fascicularis aurea I. Geoffroy Saint-Hilaire, 1830), locally called Parailla Banor is one of the 10 species of primates known to occur in Bangladesh (Ahsan 1984). The zoologists of Bangladesh first came to know about it in 1981 from the coastal mangrove forests of Whykheong area along the Naf River belt of Teknaf under Cox's Bazar Forest Division (Ahsan 1984). At that time the total population of the species in the areas was estimated to be 253 (Ahsan 1984; Khan et al. 1984). During the late 1980s the coastal-forested

Date of publication (online): 26 January 2012

Date of publication (print): 26 January 2012

ISSN 0974-7907 (online) | 0974-7893 (print)

Editor: Mewa Singh

Manuscript details:

Ms \# 02808

Received 16 May 2011

Final received 04 December 2011

Finally accepted 29 December 2011

Citation: Kabir, M.T. \& M.F. Ahsan (2012). The present status and distribution of Long-tailed Macaque Macaca fascicularis aurea (Mammalia: Primates: Cercopithecidae) in Bangladesh. Journal of Threatened Taxa 4(1): 2330-2332.

Copyright: (๑ M. Tarik Kabir \& M. Farid Ahsan 2012. Creative Commons Attribution 3.0 Unported License. JoTT allows unrestricted use of this article in any medium for non-profit purposes, reproduction and distribution by providing adequate credit to the authors and the source of publication.

Acknowledgements: Bangladesh Rifle (BDR) authority kindly extended their security and other helpful supports during our visits to the coastal belts. Both coastal and normal forest officials especially Mr. Abdur Raman, Assistant Conservator of Forests and Mr. Gazi Matiar Rahman Forest Ranger of Teknaf Forest Range Office helped us by giving some information. Many local people, fishermen and BDR also provided us with information. Mr. S.H. Hassan also accompanied us twice in the field. The study was carried out with financial support of the personal research grants of Professor Farid Ahsan and later as MPhil Fellowship grants of Mr. Tarik Kabir from the NUFU Project associated with the Department of Zoology, University of Chittagong, Chittagong. Professor Eivin Roskaft, Dr. E. Gereta Dr. B.G. Stokke and Mr. I.M. Mfunda of NTNU (The Norwegian University of Science and Technology) Trondheim, Norway, and Dr. David J. Chivers of Cambridge University, UK made some comments on the first draft of the manuscript. We thank them all.

OPEN ACGESS | FREE DOWNLOAD areas of the habitat of Long-tailed Macaque were leased for culturing shrimps. Then, the fate of the macaques became vulnerable and they probably left the area due to clearing of the forests for shrimp culture. After that few people have seen the macaques. Recently we located one group along the Naf River belt. An attempt was made to: (i) assess the present status and distribution of the Long-tailed Macaque in Bangladesh; (ii) point out causes of habitat and species loss; and (iii) recommend conservation measures.

Methods: We made 18 field trips to the sites where Long-tailed Macaques were previously recorded along the Naf River belt at Teknaf, Jimonkhali, Whykheong, Keruntoli, Chakaria Sundarbans, Maheshkhali Island and the hilly region of Teknaf(Fashiakhali, Khutakhali, Ukhia, Whykheong, Hnila, Teknaf and Baharchara (Image 1). We interviewed local people, forest officials, coastal forest officials and Bangladesh Rifles personnel (now called Border Guard Bangladesh) of Teknaf about the occurrence of the species in the area. We made boat trips from Teknaf to Whykheong and back along the coastal belt of the Naf River in search of the species.

Results: One group of Long-tailed Macaque (two adult males and one adult female (Image 2)) was

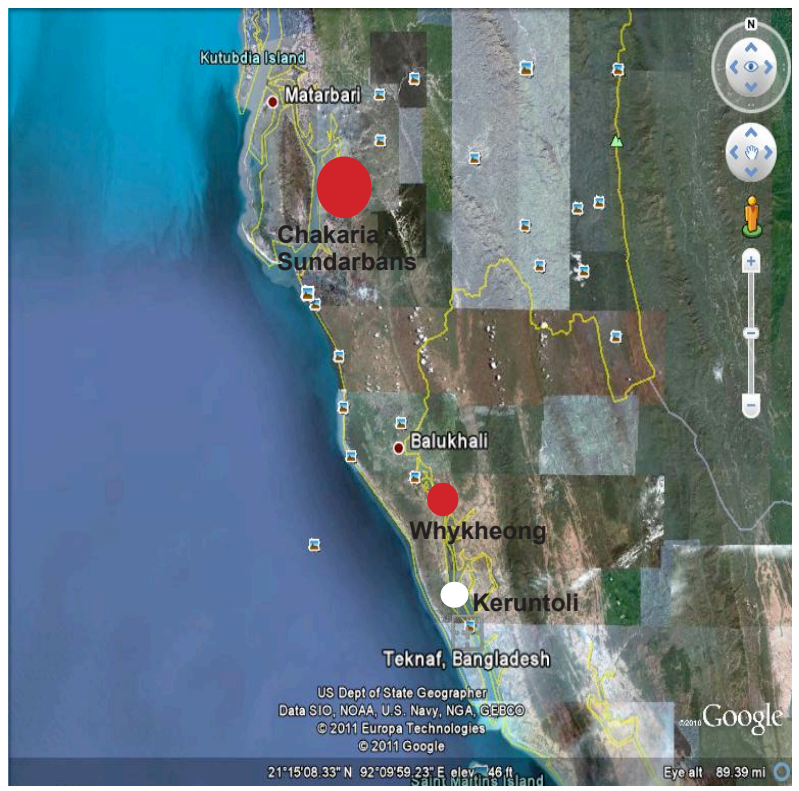

Image 1. Showing the past (red circle) and present (white circle) distribution of Long-tailed Macaque in Bangladesh (source: Google Earth) 


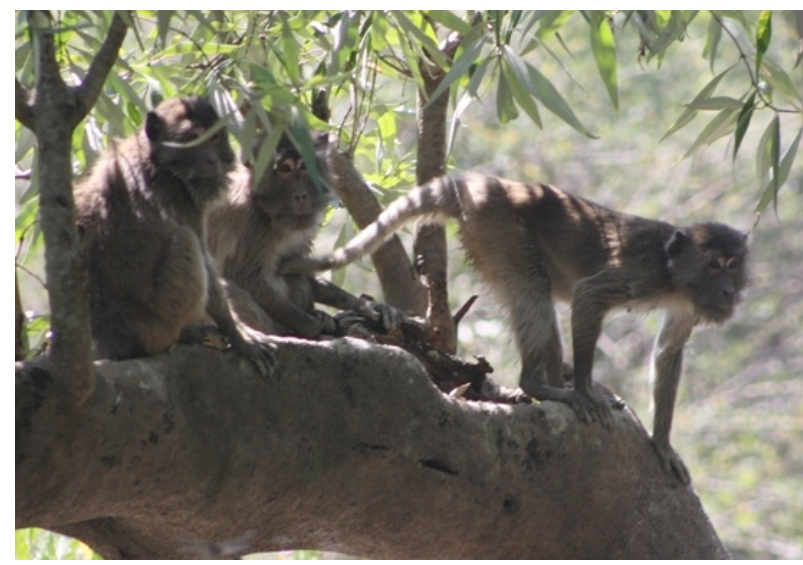

Image 2. Existing group of the Long-tailed Macaque in Bangladesh

found in the coastal forest belt along the Naf River at Keruntoli $\left(20^{0} 54.073 \mathrm{~N} \& 92^{0} 16.902 \mathrm{E}\right)$ near Teknaf Port (Image 1). Local people informed us that two Long-tailed Macaques had died, one due to a pariah dog bite and another due to unknown reasons. The approximate home range of the group was 7.91 ha during July 2010 to February 2011.

Eight species of plants (Baen Avicennia officinalis, Baro Baen Avicennia alba, Keora Sonneratia apetala, Tora Aegialitis rotundifolia, Hargoza Acanthus ilicifolius, Clerodendron sp., Chuilla Gola Dalbergia spinosa and Urighas Oryza coarctata) were found in the area occupied by macaques.

Causes of habitat destruction of the Long-tailed Macaque: The main causes of habitat destruction of the Long-tailed Macaque were found to be: (i) clearing mangrove vegetation for shrimp culture; (ii) cutting comparatively old trees for the extension of agricultural land for irrigation and for use as fuel; (iii) fishermen and fish buyers coming to the mud belt during low tide, hampering feeding of macaques; (iv) local people grazing cattle in the habitat of macaques; (v) presence of Rohinga refugees from Myanmar temporarily settled (in 1993 and still there in 2011, in two camps), destroying some habitat of macaques; (vi) establishment of new settlements along the Naf River coastal belt; and (vii) the construction of two jetties from the port to the Ansar Camp.

Discussion: Ahsan (1984) recorded a mean group size of $12(\mathrm{n}=4)$ individuals in the Whykheong area, where macaques are now absent due to the clearing of the coastal vegetation for shrimp culture and agriculture. Ahsan (1984) also estimated the total population of this macaque to be about 253 in 1981 along the Naf River belt within approximately $10 \mathrm{~km}^{2}$. In a conservation assessment workshop, the species was assessed as Critically Endangered in South Asia and Near Threatened globally (Molur et al. 2003). Hasan \& Feeroz (2010) mentioned that this species was considered locally extinct from Bangladesh in the mid 1980s without any reference and they further pointed out that it had been found in Fashiakhali in 1989.

The two groups reported by Hasan \& Feeroz (2010) in different years (five individuals in 2005 and three individuals in 2008) from Teknaf coastal vegetation, were not far from each other and it is possible that it was one group only. This is because we found one group with five individuals in 2007 and only three individuals since late 2008 in the same area. Hasan \& Feeroz (2010) also reported the presence of the Longtailed Macaque at Lal Dwip (an island of Mynmar close to Bangladesh), where now they are absent. Feeroz (2001) accounted for two groups (13 and 17 individuals) from the Chakaria Sundarbans. The Longtailed Macaque is no more present in the Chakaria Sundarbans area, and Hasan \& Feeroz (2010) assumed that possibly that population has been depleted.

Hasan \& Feeroz (2010) reported that two groups (although we predict one group only) of Long-tailed Macaque occupied an area of $16.7 \mathrm{ha}$, which is too large compared to the present home range of the recovered group of Long-tailed Macaque (7.91ha). Ahsan (1994) compiled the home range of this species as $0.12 \mathrm{~km}^{2}$, which is much smaller than the present one.

The extermination of the Long-tailed Macaque from Bangladesh in Whykheong area (where it was first sited in 1981, M.F. Ahsan, pers. obs.) was due to the clearing of coastal vegetation of that area. Consequently, most of the monkeys might have migrated to nearby Myanmar (by swimming across a small constriction of the Naf River, as this macaque is a good swimmer), which is about $200 \mathrm{~m}$ away from Bangladesh.

Twenty-two plant species were reported from Whykheong area (Khan \& Wahab 1983; Khan et al. 1984), but the present cited area supports less plant diversity (only eight species) than the previous one. This is due to the clearing of mangrove forests for shrimp culture and agriculture practices and the regenerating forests of that area have become less 
diversified. The Long-tailed Macaque consumed foods from 21 species from the Naf River coastal belt (Khan et al. 1984; Ahsan 1994).

Conclusion and Recommendations: The Long-tailed Macaque is possibly on the verge of extinction from Bangladesh, so we recommend urgent conservation measures. In this regard, the Forest Department of Bangladesh should come forward and take necessary steps along with the scientific community and local people. The present habitat at Keruntoli should be properly protected so that nobody can: (i) graze cattle, (ii) collect firewood, (iii) collect fruits of keora and chuila gola, and (iv) fish. The distance between Myanmar and Bangladesh along the Naf River coastal belt is little at Whykheong and Jimonkhali. Improving the habitats of these two areas might attract migrated Long-tailed Macaque from Myanmar. At the same time, the Government of Bangladesh should cancel leases of coastal areas of this zone for any purpose. Furthermore, attempts may be made to reintroduce some individuals of Longtailed Macaque from Myanmar as the same subspecies occurs there.

\section{REFERENCES}

Ahsan, M.F. (1984). Study of primates in Bangladesh: determination of population status and distribution of nonhuman primates in Bangladesh with emphasis on rhesus monkey. MPhil Thesis. Department of Zoology, University of Dhaka, 162pp.

Ahsan, M.F. (1994). Feeding ecology of the primates of Bangladesh, pp.79-86. In: Thierry, B., J.R. Anderson, J.J. Roeder \& N. Herrenschmidt (eds.). Current Primatology, Vol. I: Ecology and Evolution. University of Louis, Strasburgh, 398pp.

Feeroz, M.M. (2001). Species diversity and population density of non-human primates in the north-east and south-east of Bangladesh. Ecoprint 8(1): 53-57.

Hasan, M.K. \& M.M. Feeroz (2010). Distribution and status of Long-tailed Macaque (Macaca fascicularis aurea I. Geoffroy Saint-Hilaire, 1830) in Bangladesh. Journal of Threatened Taxa 2(12): 1342-1344.

Khan, M.A.R. \& M.A. Wahab (1983). Study of eco-ethology of the Crabeating Macaque, Macaca fascicularis in Bangladesh. Asiatic Society of Bangladesh, Science 9(2): 101-109.

Khan, M.A.R., M.A. Wahab \& M.F. Ahsan (1984). Ecoethology of the Crab-eating Macaque. Unpublished Report. WWF, USA.

Molur, S., D. Brandon-Jones, W. Dittus, A. Eudey, A. Kumar, M. Singh, M.M. Feeroz, M. Chalise, P. Priya \& S. Walker (eds.) (2003). Status of South Asian Primates: Conservation Assessment and Management Plan (C.A.M.P.) Workshop Report, 2003. Zoo Outreach Organisation, CBSG-South Asia, Comibatore, India, 432pp. 